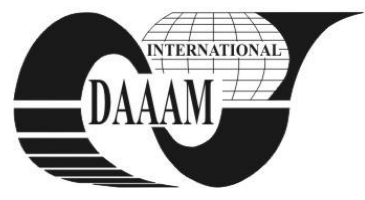

Annals of DAAAM for 2011 \& Proceedings of the 22nd International DAAAM Symposium, Volume 22, No. 1, ISSN 1726-9679 ISBN 978-3-901509-83-4, Editor B. Katalinic, Published by DAAAM International, Vienna, Austria, EU, 2011 Make Harmony between Technology and Nature, and Your Mind will Fly Free as a Bird Annals \& Proceedings of DAAAM International 2011

\title{
ACCOUNTING POLICIES ON ENVIRONMENTAL COSTS AND THEIR CALCULATION METHOD IN THE ENTITY
}

\author{
TODEA, N[icolae]; STANCIU, I[onela] C[ornelia] \& UDREA, A[na] - M[aria]
}

\begin{abstract}
The aim of this article is to present certain aspects regarding environmental costs and their calculation methods within the entity. The main objectives that were considered when writing this article included defining the concept of environmental accounting, as well as environmental costs, identifying the main classification criteria of environmental costs, and then presenting the calculation methods of environmental costs within the entity, which differ according to each area. The scientific approach is based on information from literature and on European and international practice regarding environmental costs. In order to achieve this approach we turned to research methods such as documentation, analysis, synthesis, comparison, which are part of the positivist research philosophy.
\end{abstract}

Key words: environmental protection, environmental issues, environmental accounting, environmental costs

\section{THE CONCEPTUAL FRAMEWORK OF ENVIRONMENTAL ACCOUNTING}

Environmental issues have started to be reflected in accounting only in the last half of the 20th Century. The first occurrence of the concept of environmental accounting goes back to 1970, and since then, the concept has had a growing development.

Out of many definitions of environmental accounting, the one that we're considering here was given by Bernard Christophe, who said that "environmental accounting, called also green accounting, shouldn't be confused with the mere reflection of environmental costs in traditional financial statements because it represents an efficient information system about the degree of rarefaction of natural elements, determined by the activity of entities and utilized to reduce these rarefactions and to inform third parties" (Beţianu, 2008). The same inclusive dimension is found in the definition given to environmental accounting by Steele and Powell (2002), who define it as being the identification, allocation and analysis of material flows and of environmental cash-flows in order to provide insight into environmental impacts and into the associated financial consequences. According to Bartolomeo (2000), environmental accounting provides reports for internal use, which generate environmental information that supports management decisions regarding pricing, cost control and capital budget, and it also provides reports for external use by disclosing information about the environment to the public and the financial community.

In our opinion, environmental accounting is a tool for indentifying and measuring environmental costs in order to ensure an adequate environmental performance.

\section{ENVIRONMENTAL COSTS -DEFINITION AND CLASSIFICATION}

The main component of environmental accounting is the environmental cost. Over time there have been many definitions for the concept of environmental cost, and we will analyze these definitions below.

The European Commission Recommendation 453/2001 makes the distinction between environmental costs and other costs, defining them as costs of the actions undertaken by the economic entity and by third parties in the name of an economic entity with the purpose of preventing, reducing or repairing the environmental damages resulted from operational activities. These costs include: waste storage and disposal, soil protection, underground and surface water protection, clean air and climate protection, noise reduction, biodiversity and landscape protection.

The definition given to environmental costs by the United Nations Conference on Trade and Development (UNCTAD) posits that they "comprise the costs of steps taken, or required to be taken, to manage the environmental impact of an enterprise's activity in an environmentally responsible manner, as well as other costs driven by the environmental objectives and requirements of the enterprise".

The Environmental Protection Agency defined environmental costs as being costs with a direct financial impact over entities (internal costs) and individual costs, for which the entity is not responsible (external costs). This definition represents the basis for the distinction between environmental costs, which is seen below (de Beer \& Friend, 2006):

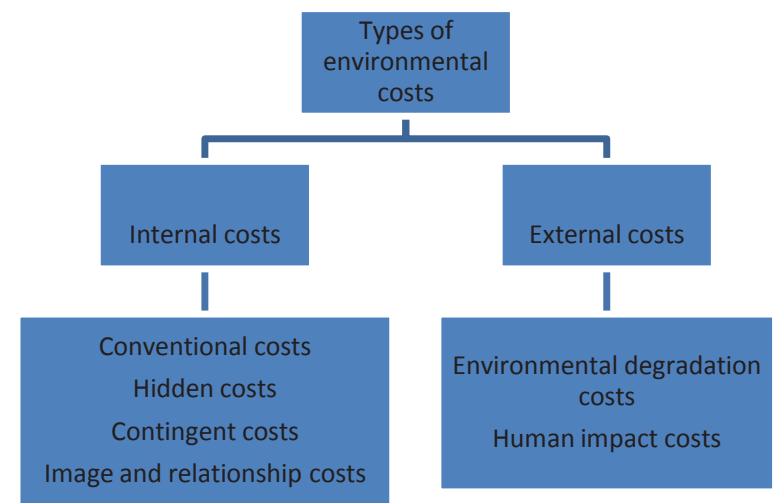

Fig. 1. Types of environmental costs

According to the Environmental Protection Agency (1995), internal costs include:

- Conventional costs, which include costs with equipments, raw materials and consumables;

- Hidden costs, which refer to the results of assigning environmental costs to indirect costs or overlooking future and contingent costs;

- Contingent costs refer to environmental costs that will not occur with certainty in the future, depending on uncertain future events, such as the costs involved in a future restoration process;

- $\quad$ PR costs are less tangible because they cover the subjective perceptions of management, clients, employees, community and regulators. This category may include costs 
of the annual environmental reports, as well as costs for environmental activities, such as planting trees.

External costs include the costs of environmental degradation for which the entities are not legally responsible and which have negative consequences on humans, property and their well being, and can't be always compensated through legal systems.

Determining the financial value of external costs is difficult, but, nevertheless, some entities are trying to approach these costs as part of their environmental accounting system.

From our point of view, environmental costs are those expenses incurred to prevent, reduce or repair damages caused to the environment, incurred at the initiative of the entity or required by the regulations and rules in place to reduce the environmental impact of the entity and to reduce the environmental risk.

\section{ENVIRONMENTAL COSTS DETERMINING METHODS WITHIN THE ENTITY}

According to Henri Jean- François (2010), the methods used by the entities to determine environmental costs are the lifecycle assessment, the environmental balance method (green balance), the full cost method, the total cost assessment method and the ABC method. These methods are not exclusive, a series of parameters are common to several methods.

The Life-cycle assessment method: the duration of the lifecycle is a method acknowledged by the ISO 14001 Environmental Management Systems, which consists of the analysis for each product of the material flows' inputs and outputs. More specifically, from an ecologic perspective, this approach analyzes the real and potential impacts of material flows over the environment.

Therefore, it includes three stages: the inventory of all flows related to energy, water, raw materials, air and emissions; the inventory of qualitative and quantitative measures that impact the environment; interpretation of the results and an assessment of possible methods to reduce environmental impacts.

The environmental balance method: consists of identifying and measuring the inputs and outputs flows of an entity, of a service, process or product in terms of energy, water, materials, waste or emissions. Therefore, it may be used during the inventory stage of the life-cycle assessment method or as a first step in other methods. A large number of environmental performance indicators can be determined based on the data supplied by this method. Traditionally, an environmental balance is done in physical, non-monetary terms.

The environmental balance method faces two major criticisms. First, the analyses of the input/output flows don't measure the environmental impact because they refer solely to the use of natural resources by the entity, overlooking what their value means for the environment. The second criticism claims that this method doesn't manage to provide monetary information.

The Full cost method: full cost is an allocation of all the costs for a product (materials, salaries, etc.) including potential and real environmental costs. With this approach, it's possible to choose products with lower costs (in terms of the environment or not). However, in terms of the environment, the full cost most often refers to taking into account the monetary value of external costs.

The Total cost assessment method: was developed by the Tellus Institute and is similar with the full costs method. While the full costs method is generally used to measure cost by product, the total cost assessment method is used to measure the cost of capital investments. In addition, the classification of the costs used to assess total cost requires identifying the costs explicitly related to the environment. The major advantage of this method is the fact it includes costs related to capital investments and to the life-cycle of the product.
The ABC method: one of the major obstacles in measuring and managing environmental costs is related to allocating these costs to the activities or products that generated them. In fact, many entities approach environmental costs per se and don't identify them as being related to the environment, thereby underestimating environmental costs. Activity based costing improves the calculus of internal costs by relating the costs generally found in indirect accounts to polluting activities and products that are determined with the help of the quantitative assessment procedures of the life-cycle.

Therefore, the $\mathrm{ABC}$ method allows an entity to allocate environmental costs to activities, and then to products. Still, it must be mentioned that using this method requires the prior identification of environmental costs. The strength of the ABC method is enhancing the understanding of the economic processes associated with each product, but it is difficult to implement within the entity.

\section{CONCLUSIONS}

The forementioned aspects show that environmental accounting is an instrument used by the entities to prevent and remove the effects of pollution, to control costs and to improve environmental performance. As can be seen, there are differences between the calculation methods of the environmental costs, some methods allowing only to identify and/or to allot environmental costs. Choosing these methods should be combined with existing methods of the entity in order to avoid excessive costs.

The results of the conducted research revealed that literature has different calculation methods for environmental costs and therefore, depending on the sector in which the entity functions, it can choose one of the presented methods. By separately managing environmental costs, by identifying the cost bearers and generators and by using cost-sharing basis and adequate costing methods, we may conclude how important is the implementation of environmental management accounting, which may contribute more efficient processes that generate costs' reductions and increased profitability.

As prospect for future research, we are considering how to actually determine environmental costs within the entity with the help of the method used by it. The conclusion that can be drawn here is that we have to make the entire activity unfold in complete harmony with the environment, ensuring sustainable development.

\section{REFERENCES}

Beţianu L. (2008), Total Quality Environmental Accounting, University "Alexandru Ioan Cuza" Publishing, ISBN:978973-703-306-2, Iaşi

Bartolomeo M et al. (2000), Environmental management accounting in Europe: current practice and future potential, The European Accounting Review, vol. 9, Issue 1

Environmental Protection Agency (1995), An introduction to Environmental Accounting as a Business Management Tool, Available from http: //www.epa.gov/, Accesed 2010-12-10

Henri Jean-François et al. (2010), Environmental costs, CMA Management Journal, Vol. 84, Issue 4, ISSN: 1490-4225

Patrick de Beer, Friend F (2006), Environmental accounting: A management tool for enhancing corporate environmental and economic performance, Ecological Economics Journal, no. 58,2006 , p. 550

*** International Federation of Accountants, Environmental Management Accounting (2005), Available from http://www.ifacnet.com/, Accessed on 2010-12- 20

*** United Nations Conference on Trade and Development (1998), Environmental financial accounting and reporting at the corporate level, Available from http://www.unctad.org/, Accessed 2010-05-10 